\title{
Sociotechnical assemblages in digital work with Aboriginal languages
}

\author{
Catherine Bow \\ College of Indigenous Futures, Arts \& Society, Charles Darwin University \\ cathy.bow@cdu.edu.au
}

Keywords: Sociotechnical assemblage; digital language resources; Indigenous languages; Northern Territory

\begin{abstract}
In this paper I consider how three digital resources for the preservation and transmission of Australian Indigenous language function as 'sociotechnical assemblages.' The three projects under consideration are a digital archive of materials from a particular era in Indigenous education in Australia's Northern Territory, an online template for presenting language data under Indigenous authority, and an online course teaching a specific Indigenous language (Bininj Kunwok) in a higher education context. Considering each of these as a sociotechnical assemblage - collections of heterogeneous elements which entangle the social and the technical - and exploring how they constitute connections and contrive equivalences between different knowledge practices, and how they resist such actions, highlights how they can open up spaces for new collaborative work.
\end{abstract}

\section{Introduction}

The use of digital technologies in the service of maintaining, preserving, revitalising and sharing language materials has become a key component of many Indigenous language projects. Collaborative knowledge practices connecting individuals, artefacts, knowledge systems and technologies generate language resources in various forms. Artefacts such as audio recordings, written texts, multimedia objects, etc. are often collected into larger units, including databases, apps, archives, and other resources which can be considered as assemblage of the social and the technical. These assemblages come into being in collaborative knowledge work, bringing together different knowledge practices in a shared space, serving a range of purposes. They also afford further knowledge work in offering possibilities for new sorts of connections and collaborations and new understandings of the nature and work of languages.

The notion of 'assemblage' refers to a collection or gathering of things or people, which may or may not be the result of a detailed plan, "a mode of ordering heterogeneous entities so that they work together for a certain time" (Müller, 2015, p. 28). While used in various ways in Science and Technology Studies (neatly summarised by Müller, 2015), the term suggests a sense of contingency and emergence, where what may have originally been envisaged has come into being in quite different ways. The use of the term in this paper draws on the definition of assemblage as provided by Watson-Verran and Turnbull (1995, p. 117):

Assemblages constitute connections and contrive equivalences between locales in knowledge systems. In research fields and bodies of technoscientific knowledge/ practice, otherwise disparate elements are rendered equivalent, general and cohesive 
... their common function is to enable otherwise incommensurable and isolated knowledges to move in space and time from the local site and moment of their production to other places and times.

This definition was subsequently developed by Verran through the juxtaposition of two quite disparate projects of "knowledge and culture work involving collection and category making" (Verran, 2009, p. 169), demonstrating how the gathering of disparate elements can produce a new entity. This new entity may be designed to serve particular functions, but should also be sufficiently flexible to allow new purposes which may not have been envisaged.

The term sociotechnical relates to the notion that "technology is never purely technological: it is also social. The social is never purely social: it is also technological" (Bijker \& Law, 1992, p. 305). Recognising the complex entanglement of these two notions helps us to looks carefully at the ways in which these assemblages are always social and always technical, and the work this allows them to do.

In this paper I consider three specific sociotechnical assemblages of Indigenous language resources I have been involved in as project manager. Through reflection on my own practice in developing and delivering these assemblages, I investigate how they 'constitute connections and contrive equivalence' between otherwise disparate elements.

Charles Darwin University (CDU) has a strong history of collaborative knowledge work with Indigenous Australians, including innovative projects exploring how new technologies can be put in service of doing the world differently. These include the longstanding Yolnu Studies program (Christie, 2008), the pioneering Teaching from Country project (Christie, 2010; Christie, Guyula, Gurruwiwi, \& Greatorex, 2013), and an inventive project on Indigenous Knowledge and Resource Management in Northern Australia (Christie, Verran, \& Gaykamangu, 2003). These projects have informed the development of digital language infrastructures for the preservation and transmission of language materials through the Living Archive of Aboriginal Languages (2012), and to support the teaching of Indigenous languages through the Digital Language Shell (2016), on which a course in one Indigenous language has been developed ('Bininj Kunwok online course', 2019). Each of these assemblages constitute connections and contrive equivalences between locales in knowledge systems, reconfiguring knowledge objects and opening them up to new knowledge practices.

\section{Assemblage 1: The Living Archive of Aboriginal Languages}

The assemblage of materials into the Living Archive of Aboriginal Languages emerged from concern for the fate of materials produced during the era of bilingual education programs in the Northern Territory (NT). These programs began in selected remote communities in the 1970 s to enable children who grew up speaking an Indigenous language to develop literacy in their home language prior to transitioning to English (Devlin, Disbray, \& Devlin, 2017). Though the policy sought to improve English proficiency rather than to document or preserve Indigenous languages, the process served to create bodies of literature in languages for those communities where bilingual programs were established. Policy changes led to the reduction of these programs over recent decades, leaving vulnerable thousands of books produced as collaborations between literacy workers, teacher linguists and language authorities, often with local illustrations or photos. The Living Archive project was a cooperative effort to collect and digitise these materials, and make them available on an open access website (Bow, Christie, \& Devlin, 2014, 2015; Christie, Devlin, \& Bow, 2014). Since 2012, the project has 
archived over 5000 books in 50 languages of the NT, mostly small booklets of 10-20 pages, containing traditional, scientific and historical knowledge, as well as literacy materials and some translations of English or other children's stories. The assemblage of these materials, including their transition from paper to digital artefacts and then collection into a bespoke knowledge infrastructure, has emerged as something quite different to what its designers imagined (Bow, 2019b).

Figure 1: Living Archive of Aboriginal Languages homepage

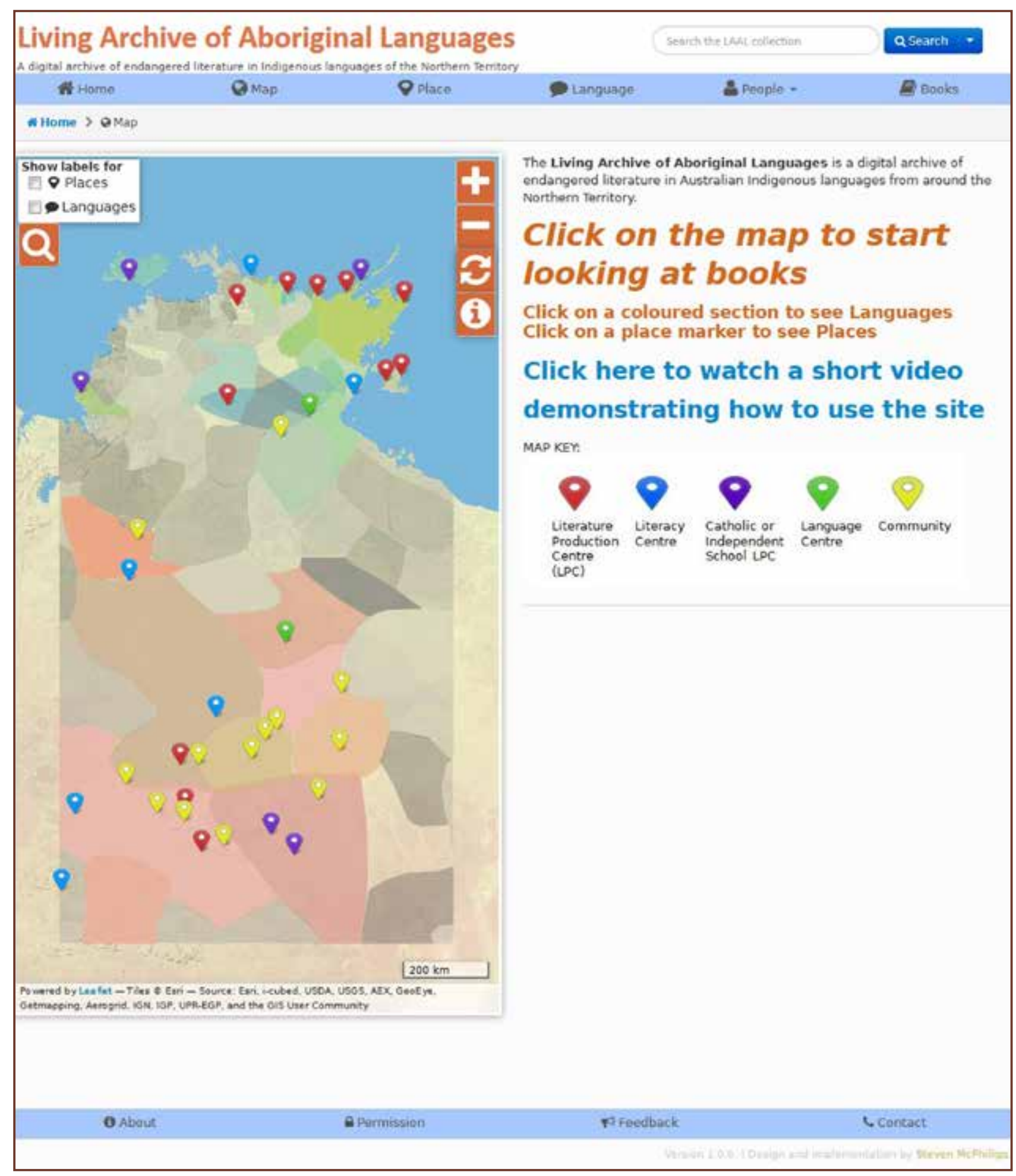


The Living Archive contrives connections between disparate elements by gathering all these materials to a single repository for preservation and access. The coding of the archive (intentionally and unintentionally) assumes particular equivalences. It connects the various components of each item - the information inscribed in the metadata, the digitised copy of the book in PDF form, the extracted text file, and the cover image thumbnail - and displays them together as a single record. It links materials to places and languages on a map which functions as the entry point to the collection (see Figure 1), and shows connections between different versions of a story where these are available, such as translations in other languages or updated versions. Search, browse and filter options in the interface were designed to enable users to make their own connections between items - whether people, languages and places, or words, topics and themes. The use of standardised forms, such as ISO 639-3 language codes (SIL International, 2015), OLAC metadata standards (Simons \& Bird, 2003), and OAIPMH protocols for harvesting (Lagoze, Van de Sompel, Nelson, \& Warner, 2002) all support connection to other collections and improve the discoverability and accessibility of the Archive and its contents. Hosting the collection on a university repository contrives sustainability into the future, and extensibility into wider linguistic and academic ecologies. Use of a permission form and Creative Commons license create connections between Indigenous and nonIndigenous practices of intellectual property management (Bow \& Hepworth, 2019).

The Living Archive constitutes equivalences by enabling diverse groups of users to access these materials. A highly visual online interface was developed to support navigation without requiring high text or technical literacy, while also maintaining standard search and browse options expected by users more familiar with library catalogues. The contents of the Archive are treated equally, with no hierarchies within the materials: a simple word book with a line drawing on each page has the same status in the Archive as an intricate creation story with complex text and rich illustration. All languages and communities and people are treated the same, whether there are thousands of speakers or none - the only difference is quantitative rather than qualitative, with some groups having greater representation, simply based on the longevity of the bilingual program. A digital archive of Indigenous language materials can take its place alongside archives of other language materials, as a corpus of literature in a recognised western context, that is still connected to its communities of origin. In WatsonVerran and Turnbull's words, the Living Archive enables otherwise incommensurable and isolated knowledges to move from the local site and moment of their production to other places and times.

There are various ways in which the Living Archive does not contrive connections or constitute equivalences - sometimes deliberately, such as not displaying items for which named contributors have not yet given permission, and not imposing classifications on the materials which would likely present a non-Indigenous perspective. Other times this lack of connections or equivalences are unrealised aspirations of the project team, such as the possibility of implementing tools from the digital humanities which could open up the Archive to new forms of visualisation and analysis, e.g. corpus building, annotation and image searching. In some cases, the connections are only partial, such as when metadata is missing which hinders search and browse functions, but also opens up to crowdsourcing of information which may be held within the communities of origin. People involved in the creation of materials can be invited to supplement metadata, e.g. where an author or illustrator is known but not listed in the book (Bow, 2019b). Each page of display only reveals partial information, and the user is invited to click to discover 'more' where possible. Not all metadata fields are considered equal, with information about titles and creators displayed more prominently than ISBNs. 
As language materials are enrolled as participants in this assemblage, certain kinds of equivalence and connectivity are assumed. The Archive assumes that a student in an urban Australian classroom can contrive connections with Aboriginal children in a remote NT classroom through the materials in the Archive, and assumes an equivalence of the curriculum that supports the knowledge work in both cases. For example, materials developed in bilingual programs can be repurposed to suit the cross-curricular requirements of the Australian Curriculum to incorporate Indigenous knowledges across all learning areas (Bow, 2016).

\section{Assemblage 2: The Digital Language Shell}

The assemblage of technologies into a Digital Language Shell emerged from a concern about the lack of Indigenous language courses available at Australian universities. Reasons given for this lack include the need for complex ongoing negotiations with language authorities, lack of materials, lack of qualified teachers, and low expectations of enrolment numbers of students (Bow, 2019a). This project proposed a technical solution to mitigate some of these challenges, and serve to facilitate universities to offer more Indigenous language courses under Indigenous authority. The Digital Language Shell was developed as an online template using free and open-source tools to allow language groups to collate, store and present their materials online without requiring expensive platforms or detailed technical knowledge (see Figure 2). It functions as an off-the-shelf, low-cost, low-tech website with a learning management system embedded, allowing users to create courses and lessons using a range of materials including video, text, image, audio, plus various forms of interactivity. Drawing on the experience of the Yolnu Studies program at CDU (Christie, 2008), the project supports the imperative to ensure that Indigenous people maintain authority and control over their materials.

As an assemblage, the Digital Language Shell contrives connections by bringing together many digital language resources into a specific configuration to suit a particular purpose. An audio file can be connected to a particular image or a grammatical explanation. The site can be configured to support various connections the language authorities, developers or users want to highlight, connecting language authorities to their materials and in turn to learners who may be in the same community or long distances away. The assemblage enables connections between the technology and the artefacts, between the designers / developers and the language authorities and the users, which can include many different kinds of audiences. For example, a range of different plugins can facilitate connections between learners and teachers, such as enabling forum posts, uploading of video and audio files, online quizzes, and synchronous interactivity, opening lines of communication across the various roles. 


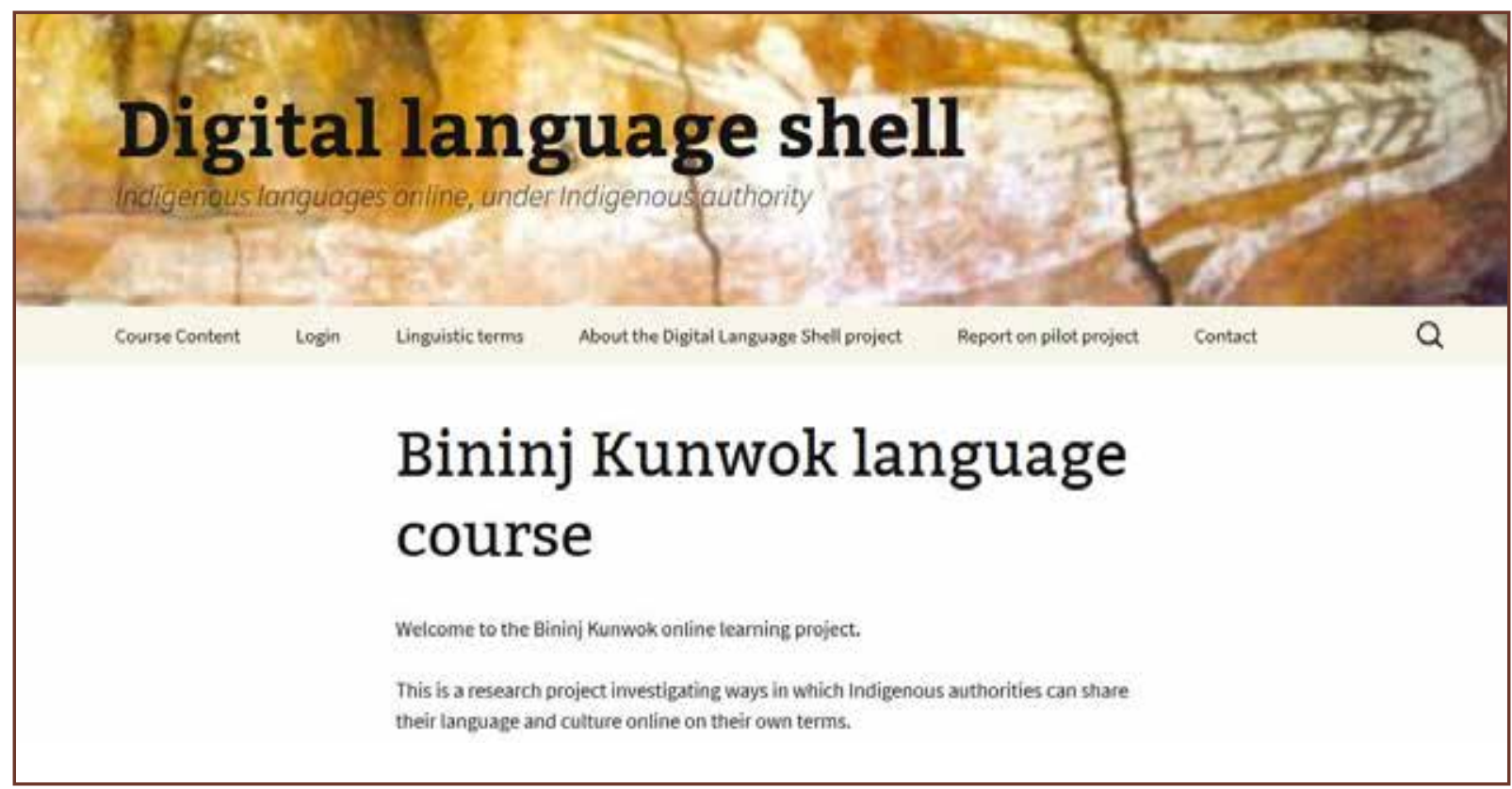

Source: screenshot from https://language-shell.cdu.edu.au/

The ways in which the Digital Language Shell constitutes equivalences is through the equal treatment of all videos, audios, texts, photos, which can be uploaded and configured without discrimination within the limits of the platform. The specific configurations of the Shell mean that no two sites would look the same, as each can be configured with its own aesthetic and functionality. The underlying WordPress platform offers an enormous range of options for various tasks, including themes to develop a unique look and feel, and plugins to enable certain features. This smorgasbord of options can be overwhelming to course designers, so the developers have chosen certain features to implement, and can offer suggestions to users wanting other functionalities. The Shell bears within it an assumption that all Aboriginal people have stories, images and ways of linking to the land, and therefore it constitutes a particular equivalence in that a template should work for any language. The assemblage is designed in such a way as to enhance the integrity of languages of any status, whether sleeping or thriving. A language group with a small range of materials from colonial era documentation, or partial word lists collected from elders with memories of the language before it stopped being used in various contexts, can use the Shell as easily as a language group with an active community of speakers who can create new resources using digital tools.

As with the previously described assemblage, certain elements were not connected or rendered equivalent, sometimes by design, such as the use of a login system to restrict access to certain users, and sometimes due to a failure in the system, such as when certain features of the platform did not work well with others due to incompatibilities in the design of the different plugins or themes. Partial connections or equivalences included the use of an institutional server, where other groups may need to invest in a server or partner with an organisation that can provide one. The template gives guidelines but not strict instructions on how it should be designed, ideally giving sufficient information to other users developing their own instantiation, without dictating how it should function. 


\section{Assemblage 3: The Bininj Kunwok online course}

The assemblage of materials into an online course teaching Bininj Kunwok language (see Figure 3) was the result of collaborative knowledge work between academics from CDU and the Australian National University (ANU) and members of the Bininj Kunwok Regional Language Centre in West Arnhem Land. It was built as a proof of concept for the Digital Language Shell, a demonstration of its implementation in a specific context (Bow, 2017). A successful pilot project with volunteer learners led to its expansion to a fully-accredited university course for delivery across a twelve-week semester.

Figure 3: Bininj Kunwok online course

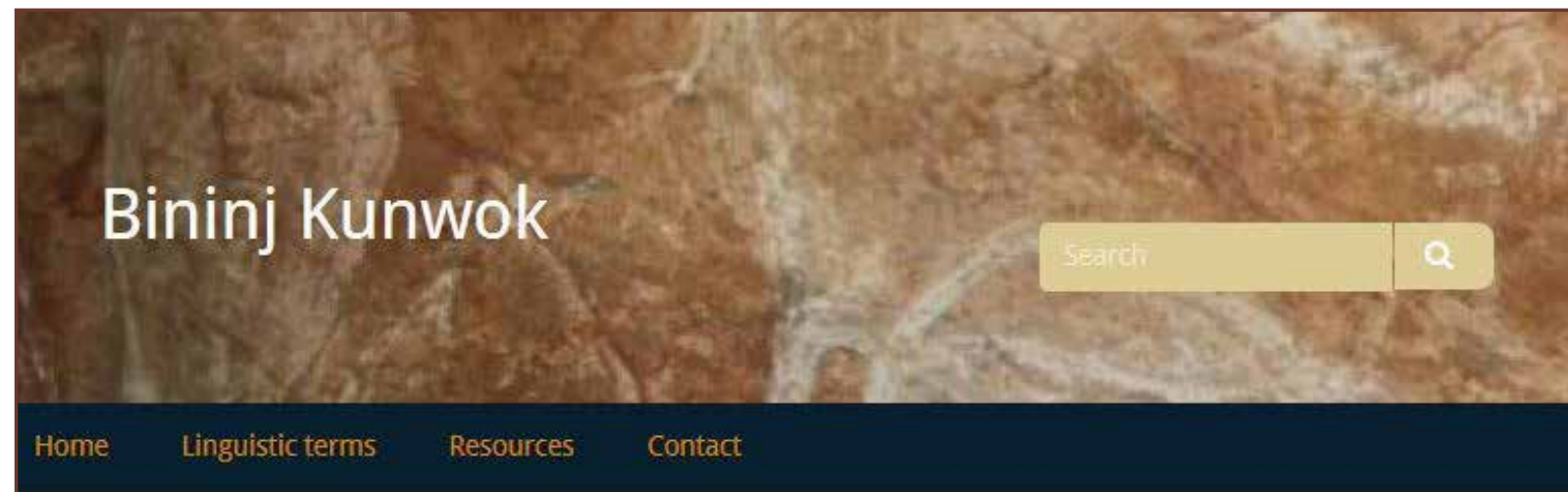

\section{Bininj Kunwok Online}

Charles Darwin University and the Australian National University, in conjunction with the Bininj Kunwok Regional Language Centre, are pleased to offer this online course.

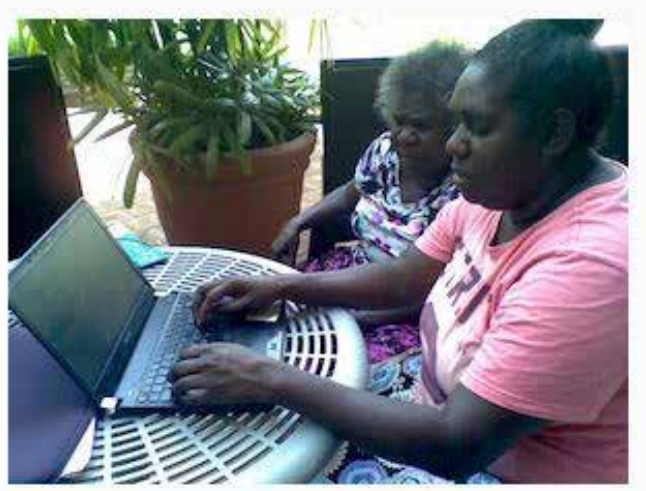

Kunwinjku is an Australian Indigenous language spoken by around 2000 people in West Arnhem Land, Northern Territory. It is part of the family of languages known as 'Bininj Kunwok' - 'bininj' meaning 'people' and 'kunwok' meaning 'language'.

Students are welcome to enrol in this unit for credit through the Australian National University or Charles Darwin University in Semester 1, 2019

The course descriptions are generic for learning an Indigenous language, but in Semester 1, 2019 the language being studied is Bininj Kunwok (Kunwinjku) 
The assemblage of materials into a language learning course for Bininj Kunwok contrives connections between disparate elements by gathering language resources and configuring them into a curriculum. For example, a unit on 'Art' uses material from a national art exhibition of a prominent Bininj artist alongside videos from the local art centre in Gunbalanya to make connections with vocabulary and grammar used in these resources. Books created in the short-lived bilingual education program in Gunbalanya in the late 1970s and early 80 s are repurposed as readers for learners to practise reading texts which incorporate the grammar and vocabulary covered in various units. The course allows learners in universities in place or online to connect to language authorities and language practices in ways that would not be possible without physically visiting a Bininj community in remote Northern Territory.

The Bininj Kunwok course constitutes equivalence by assembling disparate elements together, including materials previously created for pedagogical, promotional or entertainment purposes (books from the Living Archive, grammatical descriptions, YouTube videos), and materials newly created to fit the curriculum (audio recordings of vocabulary items and readings of books from the Living Archive, videos demonstrating particular conversational interactions or grammatical patterns) (Bow, 2019a). This assemblage allows Indigenous languages to participate in the wider world of computer-assisted language learning, which has traditionally focused on majority languages which have more resources and more potential learners, gaining recognition in a global context.

Again, there are components that are not connected or equivalent, some deliberately such as retaining the materials on the Digital Language Shell rather than rebuilding them on institutional platforms such as Blackboard or Moodle - and some due to unforeseen issues - such as the consequent need to duplicate certain information on each institutional platform to meet university requirements, and the non-alignment of semester dates between the two universities offering the course for the first time. Partial connections or equivalences can be seen in the alternate mode of access offered to workers in West Arnhem Land who wanted to take the course without having to enrol in a university degree. The Digital Language Shell enabled their participation independently of the two university structures, though only certain parts of the whole course were made available.

\section{Conclusion}

This paper has demonstrated some of the ways in which assemblages of digital language resources constitute connections and contrive equivalences between locales in knowledge systems, enabling otherwise incommensurable and isolated knowledges to move across time and space. In showing how otherwise disparate elements are rendered equivalent, general and cohesive, it is possible to consider how such assemblages enable collaborative knowledge work and can improve the ways in which this can be done.

Through these assemblages, teachers can use books created for a vernacular literacy program in the north of Australia to incorporate Indigenous knowledges into their learning areas of the Australian Curriculum. Non-Indigenous university students have the opportunity to learn an Indigenous language as part of their degree without necessarily visiting the language community in person. Indigenous language authorities become involved in curriculum and resource development to share their language and facilitate cross-cultural communication. The collaborative knowledge work involved in the careful assemblage of digital infrastructures into sociotechnical networks reconfigures existing knowledge objects in 'translating' them 
into digital formats. The alliances between people, institutions, artefacts, technologies and knowledge systems serve to create knowledge infrastructures to support the ongoing language work of communities as well as opening them up to new knowledge practices. These assemblages produce different understandings of language which are constituted as equivalent and which produce connections.

\section{References}

Bijker, W. E., \& Law, J. (Eds.). (1992). Shaping technology/building society: Studies in sociotechnical change. Cambridge, MA: MIT Press.

Bininj Kunwok online course. (2019). Retrieved from https://bininj-kunwok.cdu.edu.au/

Bow, C. (2016). Using authentic language resources to incorporate Indigenous knowledges across the Australian Curriculum. Learning Communities: International Journal of Learning in Social Contexts, 20, 20-39. https://doi.org/10.18793/LCJ2016.20.03

Bow, C. (2017). Activating community-based Indigenous language and culture resources for university teaching - Report on the development of a digital shell and pilot delivery. Canberra, ACT: Department of Education and Training.

Bow, C. (2019a). Collaboratively designing an online course to teach an Australian Indigenous language at university. Babel, 54(1/2), 54-60.

Bow, C. (2019b). Diverse socio-technical aspects of a digital archive of Aboriginal languages. Archives and Manuscripts, 47(1), 94-112. https://doi.org/10.1080/01576895.2019.1570282

Bow, C., Christie, M., \& Devlin, B. (2014). Developing a Living Archive of Aboriginal Languages. Language Documentation \& Conservation, 8, 345-360.

Bow, C., Christie, M., \& Devlin, B. (2015). Shoehorning complex metadata in the Living Archive of Aboriginal Languages. In A. Harris, N. Thieberger, \& L. Barwick (Eds.), Research, Records and Responsibility: Ten years of PARADISEC (pp. 115-131). Sydney, NSW: Sydney University Press.

Bow, C., \& Hepworth, P. (2019). Observing and respecting diverse knowledge traditions in a digital archive of Indigenous language materials. Journal of Copyright in Education and Librarianship, 3(1), 1-36. https://doi.org/10.17161/jcel.v3i1.7485

Christie, M. (2008). Yolngu Studies: A case study of Aboriginal community engagement. Gateways: International Journal of Community Research and Engagement, 1, 31-47.

Christie, M. (2010). Teaching from country, learning from country. Learning Communities: International Journal of Learning in Social Contexts, 2, 6-17.

Christie, M., Devlin, B., \& Bow, C. (2014). The Birth of the Living Archive: An emerging archive of Australian Aboriginal languages and literature. Archifacts, October 2014, 48-63.

Christie, M., Guyula, Y., Gurruwiwi, D., \& Greatorex, J. (2013). Teaching from Country: Connecting remote Indigenous knowledge authorities with university students around the world. In L. Ormond-Parker, A. Corn, C. Fforde, K. Obata, \& S. O'Sullivan (Eds.), Information Technology and Indigenous Communities (pp. 127-138). Canberra, ACT: AIATSIS Research Publications.

Christie, M., Verran, H., \& Gaykamangu, W. (2003). IKRMNA - making collective memory with computers. Retrieved from Indigenous Knowledge and Resource Management in Northern Australia website: http://www.cdu.edu.au/centres/ik/ikhome.html

Devlin, B., Disbray, S., \& Devlin, N. R. F. (Eds.). (2017). History of Bilingual Education in the Northern Territory. Singapore: Springer.

Digital Language Shell. (2016). Retrieved from https://language-shell.cdu.edu.au/

Lagoze, C., Van de Sompel, H., Nelson, M., \& Warner, S. (2002, June 14). Open Archives Initiative-Protocol for Metadata Harvesting-V.2.0. Retrieved from https://www.openarchives.org/OAl/openarchivesprotocol.html 
Living Archive of Aboriginal Languages. (2012). Retrieved from Living Archive of Aboriginal Languages website: http://laal.cdu.edu.au/

Müller, M. (2015). Assemblages and Actor-networks: Rethinking Socio-material Power, Politics and Space. Geography Compass, 9(1), 27-41. https://doi.org/10.1111/gec3.12192

SIL International. (2015). ISO 639-3. Retrieved from ISO 3 Registration Authority website: http://www-01.sil.org/ iso639-3/default.asp

Simons, G., \& Bird, S. (2003). Building an open language archives community on the OAI foundation. Library Hi Tech, 21(2), 210-218.

Verran, H. (2009). On Assemblage: Indigenous knowledge and digital media (2003-2006), and HMS Investigator (1800-1805). Journal of Cultural Economy, 2(1-2), 169-182. https://doi.org/10.1080/17530350903064188

Watson-Verran, H., \& Turnbull, D. (1995). Science and Other Indigenous Knowledge Systems. In S. Jasanoff, G. E. Markle, J. C. Peterson, \& T. Pinch (Eds.), Handbook of Science and Technology Studies (pp. 115-139). Thousand Oaks, CA: Sage. 